\title{
Impact of Organizational Culture on Business Process Performance: An Investigation in the Financial Services Industry
}

\author{
Jürgen Moormann ${ }^{a}$ and Corinna Grau ${ }^{b}$ \\ ProcessLab, Department of Management, Frankfurt School of Finance \& Management, \\ Sonnemannstr. 9-11, 60314 Frankfurt a.M., Germany; \\ aj.moormann@fs.de, ${ }^{b}$ c.grau@fs.de
}

\begin{abstract}
Keywords: Business process management, cultural dimensions, organizational culture, process performance.
\end{abstract}

\begin{abstract}
Organizational culture is increasingly acknowledged to have a substantial impact on the performance of business processes. Hence, companies should be aware of their culture and the underlying values and perceptions when it comes to conducting and improving their processes. This paper addresses these issues and presents results of an empirical study carried out at a large European financial services company. The results confirm a strong positive influence of organizational culture on process performance. Furthermore, the results provide evidence that driving forward strategic orientation, structural conditions, as well as management and leadership contribute to higher process performance.
\end{abstract}

\section{Introduction}

Today, a large number of methods, techniques, and tools for business process management (BPM) are available. Thus, the more technical side of BPM is no longer a headache for companies. Matters are quite different when it comes to implementation. Often process-related projects fail or deliver disappointing results. A major reason for an unsatisfying deployment of BPM is the insensitivity concerning attitude and behavior of the involved employees including the management levels [1]. Scepticism, mistrust, or even outright rejection of change-related initiatives are common observations in practice. Hence, companies should consider their culture and the underlying values and perceptions which might influence the success of BPM initiatives.

Although the issue of implementation is highly relevant the interaction between both fields, organizational culture and process management, is only rarely examined [2]. Yet there are plenty of questions companies need to find answers for, such as: Does organizational culture really impact the performance of processes? If so, what can be done from a management's perspective to ensure process thinking becomes accepted within the organization?

This paper aims to find answers to these research questions. Since literature is still scarce in this area we base our findings on an investigation conducted in a large financial services group in Europe. In the following section we briefly explain the current status of organizational culture and its relation to BPM. In the next section the case study is presented. Particularly it is shown which steps we undertook to measure organizational culture and process performance. Based on the results, we derive suggestions how to deal with culture in a BPM context. The final section concludes.

\section{Background}

Organizational Culture. In theory and practice there is a broad agreement concerning the relevance of cultural aspects when introducing new ideas and concepts to companies and other organizations. In general, organizational culture may be described as a pattern of basic assumptions discovered or developed within a certain group, while that group learns how to deal with internal and external challenges [3]. If these assumptions prove of value, they are perceived as valid and communicated further to new members of the group. Thus, culture is organization-specific and can be seen as a rather 
constant, though not unchangeable factor, which has an influence on the relations and operations within an organization [4].

Schein [3] explains how and why culture develops within organizations by describing the need for integration and sense in the actions of the organization's members. This essential need for integration in a social group and differentiation against others leads to the evolution of shared values, beliefs, and procedures which prove successful and therefore are asserted over time. Such shared elements are transferred to new members of the organization as part of the socialization process. Schein's concept of interdependent cultural levels is based on this explanation and became a fundamental model in organizational psychology.

Relation of Organizational Culture to BPM. BPM is a multidisciplinary field, which developed over time from a rather IT-driven approach to a broader managerial topic. Nowadays the concept of BPM is to be understood as a holistic field including various aspects such as legal, economic, and especially human and organizational facets [5]. Hence, the performance of an organization is driven by the co-action of people and processes which can be summarized as the organization's culture.

In literature we find a broad consensus that cultural aspects are a key factor for the success or failure of BPM projects [6]. Consequently, the successful implementation of BPM in an organization assuring a high level of process performance has to match with an appropriate culture [7].

\section{Methodology and Case}

To analyze how organizational culture and process performance interrelate we refer to a case study. The case is based on a real company. Data were captured from the company's IT systems and from questionnaires. Furthermore, we conducted interviews with employees and managers at different hierarchical levels. While the name of the company, Allfinance Group (AFG), is fictitious, the content presented in this paper is based on a real situation, a real process, and real data.

AFG is a Europe-based company offering a broad spectrum of banking and insurance products. It totals more than 10,000 employees and runs a network of hundreds of branches. Although the range of products and services is comprehensive, the business of selling, approving, and settling of mortgage loans is the core business of AFG. The company therefore relies heavily on well-functioning information systems to be able to process loan applications fast but with a constant eye on the related credit and operational risks.

The loan approval process of AFG consists of successive process steps: acceptance and scanning of the submitted application; formal check of completeness of the application; fast pre-check of the loan application in order to respond quickly to the customer request with a preliminary assessment; property valuation; detailed assessment of the application including the final lending decision. Property valuation is conducted by an external company.

Furthermore, the loan application process is differentiated into several production lanes. The assignment to the respective lane depends on the type, volume, complexity, and risk level of the submitted loan applications. The process is supported by several IT systems and employs about 400 persons (full-time equivalents, FTEs) handling roughly 100,000 applications per year. For this process, AFG runs three operating sites with exactly the same process steps and the same organizational structure. 209 employees working in the loan application process participated in our study (response rate $51.7 \%$ ).

\section{Data and Results}

Measuring organizational culture. Since organizational culture is a not directly observable construct [5], it has to be operationalized if we want to analyze its impact on process performance. Although manifold research approaches are suggested they mostly rely on the Organizational Culture Profile (OCP) developed by O'Reilly et al. [8]. These authors suggest inquire 54 "value statements" to capture an organization's values and norms. 
In analogy to the OCP Jöns et al. [9] developed a "short scale" to assess culture in companies. This scale (Corporate Culture Scale, CCS) is composed of the core dimensions of several prevalent prominent culture assessment instruments and is based on the theoretical understanding of organizational culture according to Schein [5]. The CCS assesses the shared values and norms of an organization as well as the structures and processes of the company from the viewpoint of the employees. The cultural dimensions, which have been validated in several case studies and surveys [see e.g. 10], are: strategic orientation of the company, structural conditions, cooperation and teamwork, as well as general management and leadership.

To assess AFG's organizational culture with regard to the employees in the loan approval process, we conducted a paper-pencil questionnaire survey based on the Corporate Culture Scale. The participants were asked about the extent of their individual agreement with several bipolar statements referring to the aforementioned cultural dimensions. In addition, we gathered data with regard to employee satisfaction.

Measuring process performance. The relation between organizational culture and business processes can only be investigated if process data is captured. In our case we were able to collect real process data from AFG's IT systems. We measured the performance directly by means of a productivity performance indicator per employee. This data was derived from the production report of AFG. The report is based on a comprehensive workflow management system. The productivity performance indicator is calculated as the total hours worked in relation to the amount of processed loan applications during the analyzed work period.

For our investigation we developed a Structured Equation Model. Most importantly, the path coefficients between the variables organizational culture and process performance showed a high statistical significance of 0.288 (significance level of 5\%). This result confirms the theoretically presumed influence of organizational culture on process performance.

As expected, the mediator variable employee satisfaction is positively impacted by the organizational culture (0.824). This complies with the theoretical assumption that a culture, which is observed as positive, leads to an increased employee satisfaction. However, the path coefficient between the variables employee satisfaction and process performance shows a statistically insignificant value of -0.024 , i.e. there is no influence of employee satisfaction on process performance observable and thus no mediating effect in this regard.

We also calculated the Squared Multiple Correlations. They describe the percentage of the constructs' variance which is explained by the variables. For the endogen variable process performance the value is 0.083 , i.e. $8.3 \%$ of the variance of process performance can be explained by corporate culture. For the variable employee satisfaction the value is even at 0.679 . Thus, the variance of satisfaction of the employees is explained by AFG's corporate culture with almost $68 \%$.

\section{Discussion}

The purpose of our case study was to investigate how organizational culture interrelates with business processes and which cultural dimensions are supportive for high business process performance. The results of the case provide evidence that fostering the strategic orientation, structural conditions, as well as management and leadership contribute to better process performance measured in terms of the employees' productivity. From the perspective of a company's management it is therefore reasonable, to positively influence the cultural dimensions to ultimately increase process performance.

If employees and managers can prove that their practices and measures are of value according to the organization's culture dimensions then such procedures will be adapted in the future. The entirety of behavior patterns will consolidate to an organizational culture which in turn will affect the process performance in a positive way. However, such a learning process cannot be accomplished short-term but develops in the course of time.

Furthermore, the case of AFG showed that sub-cultures of the organization can be compared with each other. Results concerning this matter reveal that different sub-cultures within a company 
strongly impact the performance of its business processes. Analysis of sub-cultures can be performed for regional organizational units, national companies, subsidiaries etc. The issue of sub-cultures is also relevant for mergers and acquisitions and the integration of organizational units into the parent company.

Collecting and analyzing data at the intersection of organizational culture and process management is not only a comprehensive task but also highly sensitive. Since data on workplace level are concerned when conducting an investigation like this the agreement of the workers' council is needed - at least in most European companies. In the case presented here, the entire investigation had been reviewed well in advance by the company's management as well as the workers' representatives and had been explicitly supported by both boards.

\section{Conclusion}

Up to now there is only little attention on organizational culture with regard to BPM. This applies equally to academia and practice. Even if an organizational unit exists which is concerned with process management, mostly there is no linkage to culture aspects of the organization. The case study presented here raises awareness of this issue and allows for conclusions how to influence the culture of an organization in the pursuit of higher process performance. The results indicate that, by attaching more importance to employee information and participation and revealing high confidence in the employees, managers can exert positive influence on the performance of their company's business processes.

Along this path the culture of an organization becomes economically relevant. Successful process management in all types of organizations needs a supportive culture. Since cultural changes do not happen on a short notice, establishing and sustainably anchoring process thinking on all hierarchical levels must be pursued continually.

\section{References}

[1] P. Ravesteyn, R. Batenburg, Surveying the critical success factors of BPM-systems implementation, Bus Proc Manag J, 16(3) (2010) 492-507.

[2] C. Grau, J. Moormann, Investigating the Relationship between Process Management and Organizational Culture: Literature Review and Research Agenda, Manag Organ Stud, 1(2) (2014) 1-17.

[3] E.H. Schein, Organizational Culture and Leadership, Jossey-Bass, San Francisco, 1985.

[4] S. Beugelsdijk, C.I. Koen, N.G. Nooderhaven, Organizational culture and relationship skills, Organ Stud, 27(6) (2006) 833-854.

[5] M. Rosemann and J. vom Brocke, The six core elements of business process management, in: J. vom Brocke, M. Rosemann (Eds.), Handbook on Business Process Management, vol. 1, Berlin Heidelberg, 2010, 107-122.

[6] M. Kohlbacher, S. Gruenwald, S., Process orientation: conceptualization and measurement, Bus Proc Manag J, 17(2) (2011) 267-283.

[7] J. vom Brocke, T. Sinnl, Culture in business process management: a literature review, Bus Proc Manag J, 17(2) (2011) 357-377.

[8] C.A. O'Reilly, J. Chatman, D.F. Caldwell, People and Organizational Culture: A Profile Comparison Approach to Assessing Person-Organization Fit, Acad Manage J, 34(3) (1991) 487-516.

[9] I. Jöns, M. Hodapp, K. Weiss, Kurzskala zur Erfassung der Unternehmenskultur, 2005, information on http://psydok.sulb.uni-saarland.de/volltexte/2006/690/, viewed May 2014. 